\title{
The risk factors related to the severity of pain in patients with Chronic Prostatitis/Chronic Pelvic Pain Syndrome
}

Jing Chen ${ }^{1,2}$, Haomin Zhang ${ }^{3}$, Di Niu ${ }^{1,2}$, Hu Li $^{1,2}$, Kun Wei ${ }^{1,2}$, Li Zhang ${ }^{1,2}$, Shuiping Yin ${ }^{1,2}$, Longfei Liu ${ }^{5}$, Xiansheng Zhang ${ }^{1,2,4}$, Meng Zhang ${ }^{1,2,4,6^{*}}$ and Chaozhao Liang 1,2,4*

\begin{abstract}
Background: Chronic Prostatitis/Chronic Pelvic Pain Syndrome (CP/CPPS) is a disease with diverse clinical manifestations, such as pelvic pain or perineal pain. Although recent studies found several risk factors related to the pain severity of CP/CPPS patients, results were inconsistent. Here, we aimed to identify novel risk factors that are closely related to the severity of pain in patients with CP/CPPS.
\end{abstract}

Methods: We retrospectively collected the clinical records from patients with CP/CPPS from March 2019 to October 2019. The questionnaire was used to obtain related parameters, such as demographics, lifestyle, medical history, etc. To identify potential risk factors related to pain severity, we used the methods of univariate and multivariate logistic regression analyses. Further, to confirm the relationship between these confirmed risk factors and CP/CPPS, we randomly divided CP/CPPS patients into the training and the validation cohorts with a ratio of 7:3. According to the co-efficient result of each risk factor calculated by multivariate logistic regression analysis, a predicting model of pain severity was established. The receiver operating characteristic curve (ROC), discrimination plot, calibration plot, and decision curve analyses (DCA) were used to evaluate the clinical usage of the current model in both the training and validation cohorts.

Results: A total of 272 eligible patients were enrolled. The univariate and multivariate logistic regression analysis found that age [odds ratio (OR): $2.828,95 \%$ confidence intervals (Cl): 1.239-6.648, $P=0.004$ ], holding back urine (OR: $2.413,95 \% \mathrm{Cl}: 1.213-4.915, P=0.005)$, anxiety or irritability (OR: $3.511,95 \% \mathrm{Cl}: 2.034-6.186, P<0.001)$, contraception (OR: 2.136, 95\% Cl:1.161-3.014, $P=0.029$ ), and smoking status (OR: 1.453, 95\% Cl: 1.313-5.127, $P=0.013$ ) were the risk factors of pain severity. We then established a nomogram model, to test whether these factors could be used to predict the pain severity of CP/CPPS patients in turn. Finally, ROC, DCA, and calibration analyses proved the significance and stability of this nomogram, further confirmed that these factors were closely related to the pain severity of CP/ CPPS patients.

\footnotetext{
*Correspondence: zhangmeng1930@126.com; liang_chaozhao@ahmu.edu.cn

${ }^{4}$ Anhui Province Key Laboratory of Genitourinary Diseases, Anhui Medical University, Hefei, People's Republic of China

${ }^{6}$ Institute of Urology of Shenzhen University, The Third Affiliated Hospital

of Shenzhen University, Shenzhen Luohu Hospital Group, Shenzhen,

People's Republic of China

Full list of author information is available at the end of the article
} original author(s) and the source, provide a link to the Creative Commons licence, and indicate if changes were made. The images or other third party material in this article are included in the article's Creative Commons licence, unless indicated otherwise in a credit line to the material. If material is not included in the article's Creative Commons licence and your intended use is not permitted by statutory regulation or exceeds the permitted use, you will need to obtain permission directly from the copyright holder. To view a copy of this licence, visit http://creativecommons.org/licenses/by/4.0/. The Creative Commons Public Domain Dedication waiver (http://creativeco mmons.org/publicdomain/zero/1.0/) applies to the data made available in this article, unless otherwise stated in a credit line to the data. 
Conclusions: We identify age, holding back urine, anxiety or irritability, contraception, and smoking are risk factors closely related to the pain severity in patients with CP/CPPS. Our results provide novel inspirations for clinicians to design the personalized treatment plan for individual CP/CPPS patient who has suffered different encounters.

Keywords: Chronic prostatitis, Risk factors, Pain, Nomogram, Personalized treatment

\section{Background}

Prostatitis is a common urologic disease [1, 2], with studies reporting that during their lifetime, approximately $35-50 \%$ of men will suffer from prostatitis. The morbidity of prostatitis is higher in men who are not over 50-year-old [3]. According to previous work, we know that the prevalence rate of chronic prostatitis in Chinese males is approximately $8.4 \%$ [4]. Based on a proposal from the National Institutes of Health (NIH) [5], prostatitis is divided into four categories; of them, Category III, which is defined as chronic prostatitis or chronic pelvic pain syndrome (CP/CPPS), accounts for most cases of prostatitis [6]. CP/CPPS has a variety of clinical manifestations, such as pelvic pain or perineal pain, irritative or obstructive voiding symptoms, sexual dysfunction, or psychological disorders, and is without any evidence of urinary tract infection $[7,8]$. Commonly, chronic pelvic pain occurs with pelvic floor tenderness, thus the patients will feel pain at the time of palpation [9].

Clinically, doctors always apply NIH-CPSI to judge the severity of chronic prostatitis. According to the subscores for pain, the pain levels are graded as mild ( 0 to 7 ), moderate ( 8 to 13 ), and severe (14 to 21 ). A recent study showed that the relationship between pain with the quality of life (QoL) in CP/CPPS patients was more important than urinary symptoms and the pain severity was more important than pain localization/ type [10]. So, studying the risk factors for pain severity and clarifying the pain severity are helpful in improving the strategy of individualized phenotypically guided treatment. Although recent studies had found several risk factors related to the pain of $\mathrm{CP} / \mathrm{CPPS}$ patients, results were inconsistent. Some studies had shown that a sedentary lifestyle, smoking, and stress were potential risk factors for the pain in patients with CP/CPPS [11]. But other studies showed that cigarette smoking was not related to the pain in patients with CP/CPPS [12]. Therefore, studying the risk factors for the pain severity in patients with CP/CPPS is particularly important for designing the personalized treatment plan.

In this study, we recorded the NIH-CPSI scores and other parameters from the outpatients with CP/CPPS to explore the risk factors related to the pain severity in patients with CP/CPPS and establish a predicting model of it.

\section{Methods}

\section{Population selection}

From March 2019 to October 2019, approximately 322 patients were diagnosis of CP/CPPS according to physical examination, microbiologic localization cultures, laboratory testing of stamey test, urodynamic studies and the UPOINTs classification [13] in the clinic of the First Affiliated Hospital of Anhui Medical University; we recorded the information from those patients. This study was approved by the Institutional Review Board of the First Affiliated Hospital of Anhui Medical University. Each patient had signed informed consent. The inclusion criteria for CP/CPPS patients were as follows: (1) symptoms lasting for at least 3 months; (2) discomfort or pain in the pelvic area or perineum that participants were excluded from the study if they had the urologic disease, such as acute prostatitis or bacterial prostatitis, urinary tract infection, urinary tuberculosis, bladder stone, interstitial cystitis, urethritis [14], and (3) the score of NIHCPSI $\geq 4$ [15]. The patients whose age was older than 50 years underwent a test of serum PSA based on the cut point of less than $4.0 \mathrm{ng} / \mathrm{ml}$ to exclude prostate cancer [16]. The patients who had benign prostatic hyperplasia $(\mathrm{BPH})$ that the prostate ultrasound showed the prostate volume greater than $2^{*} 3^{*} 4 \mathrm{~cm}$ with the post-void residual urine volume of $50 \mathrm{ml}$ were ruled out. Of all 322 recorded patients, 50 were excluded because of missing baseline values for continuous variables.

\section{Records of the variables}

From the available records that we obtained from the $\mathrm{CP} / \mathrm{CPPS}$ patients; according to some studies of the risk factors for CP/CPPS and the pain of CP/CPPS [11], the 11 variables were about basic information, lifestyle, and medical history were selected for further analysis. The sedentary lifestyle was defined as sitting or lying down when took part in an activity, such as reading, watching television, driving [17]. Holding back urine was defined as that waiting until the last second to go to the bathroom to pee [18]. In China, the main contraceptive method was the use of condoms, so in our study, the contraceptive method was set as the use of condoms. The questionnaire of the Self-Rating Anxiety Scale (SAS) was used to judge whether patients with CP/CPPS had the diagnosis of anxiety. When the scores of SAS was more than 50, the patients were diagnosed with anxiety [19]. $100 \mathrm{ml}$ of 
beer per week differed significantly from $100 \mathrm{ml}$ of liquor or spirits. To accurately assess the alcohol intake of patients, we uniformly defined the patient's alcohol intake as grams of alcohol intake per week. According to the number of cigarettes daily in Paul's study, we divided smokers into two groups: daily smoker of $<10$ cigarettes and daily smoker of $\geq 10$ cigarettes [20]. Skewed data were log-transformed or coded as categorical variables, and the detailed information was presented in Additional file 1: Table S1.

\section{Statistical analysis}

For the information of the patients, the normality was checked by the Shapiro-Wilk test and the demographic characteristics were compared by $\mathrm{X}^{2}$-test. When the $\mathrm{p}$-value was lower than 0.05 , the difference of risk factors between mild pain and moderately to severely pain groups was considered statistically significant. Univariate logistic regression analysis and multivariate logistic regression analysis were used to estimate those potential factors. The variables were considered as odds ratios (ORs), 95\% confidence intervals (CIs), and $P$-values. To confirm the relationship between these confirmed risk factors and CP/CPPS, we randomly divided CP/CPPS patients into the training and the validation cohorts at a ratio of 7:3 (Fig. 1) to establish a predicting model of pain severity in patients with CP/CPPS. Based on these results of multivariate logistic regression analysis, a predicting model was created by using the "rms" package in
$\mathrm{R}$ version 3.6.1. To assess the discrimination, calibration, and clinical usage of this predicting model, the methods of ROC, calibration plot, and DCA were executed. The validation cohort was used to confirm the significance and performance of this model.

\section{Results}

Risk factors for pain severity in patients with CP/CPPS

According to the NIH-CPSI's subscores for pain, all patients were divided into two groups: CP/CPPS patients with mild pain (less than eight scores) and patients with moderate to severe pain (higher than a score of eight). The variables included age, BMI, white cells in the urine, sedentary, holding back urine, anxiety or irritability, sex life, contraception, past medical history, alcohol consumption, and smoking. The distributions of variables among CP/CPPS patients and the $P$-value of variables between the two groups were shown in Table 1. According to the univariate logistic regression analysis, age $(P=0.041)$, BMI $(P=0.007)$, holding back urine $(P=0.004)$, anxiety or irritability $(P<0.001)$, contraception $(P=0.012)$ and smoking $(P<0.001)$ were potential risk factors for the pain severity in patients with $\mathrm{CP} / \mathrm{CPPS}$. Multivariate logistic regression analysis was used to measure the variables to exclude the internal effects of the participants. We found that age [OR: 2.828, 95\% CI: 1.239-6.648, $P=0.004]$, holding back urine (OR: $2.413,95 \%$ CI: $1.213-$ 4.915, $P=0.005$ ), anxiety or irritability (OR: $3.511,95 \%$ CI: 2.034-6.186, $P<0.001$ ), contraception (OR: 2.136,

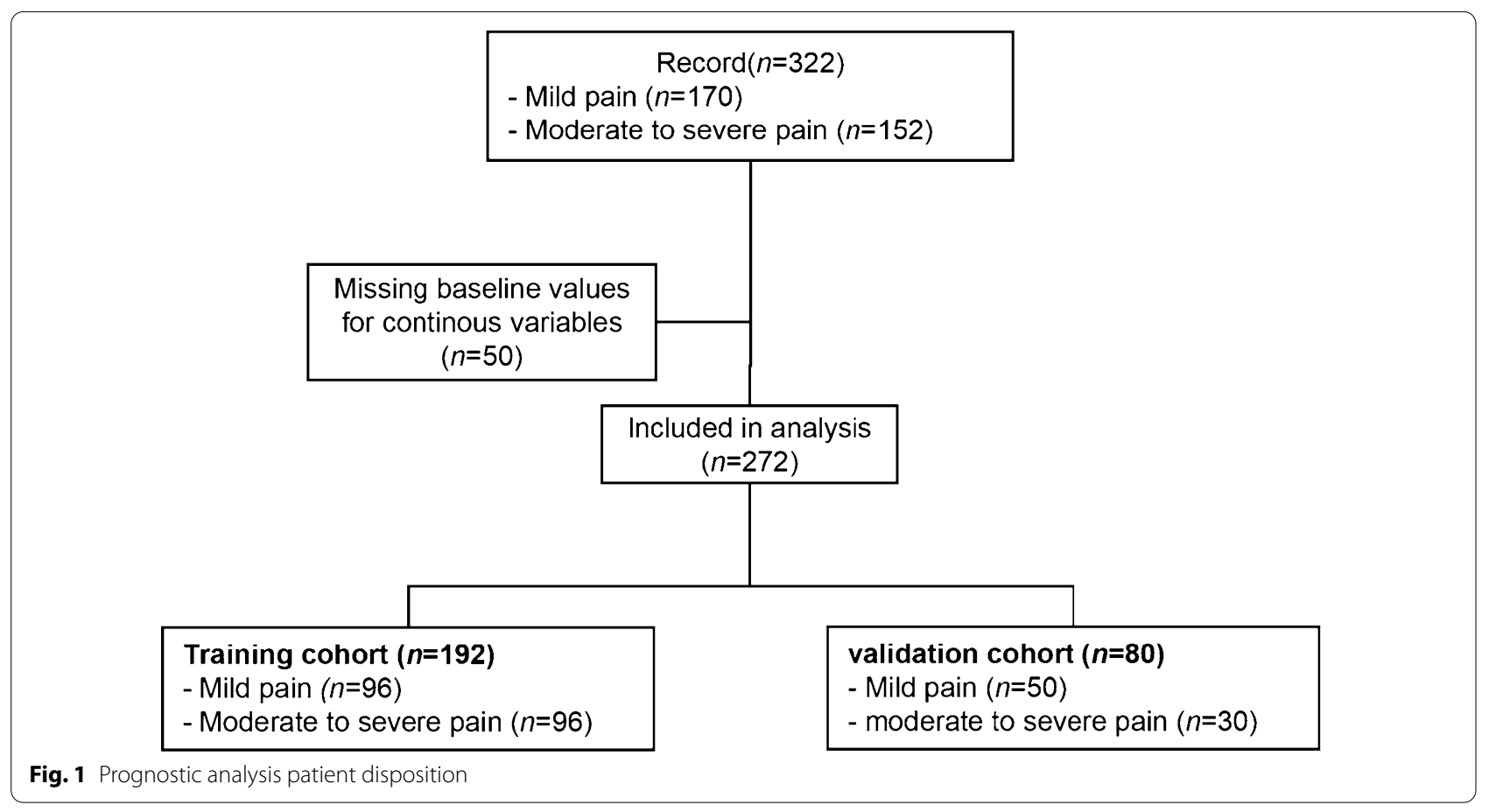


Table 1 Comparison of risk factors in pain severity in patients of CP/CPPS

\begin{tabular}{|c|c|c|c|}
\hline Characteristic & $\begin{array}{l}\text { Mildly pain } \\
(n=146)\end{array}$ & $\begin{array}{l}\text { Moderately } \\
\text { to severely } \\
\text { pain } \\
(n=126)\end{array}$ & $P$ value \\
\hline \multicolumn{4}{|l|}{ Age, years } \\
\hline$\leq 30$ years & $60(41.10)$ & $43(34.13)$ & \multirow[t]{4}{*}{$0.046^{*}$} \\
\hline 30 to $\leq 40$ years & $52(35.61)$ & $36(28.57)$ & \\
\hline 40 to $\leq 50$ years & $22(15.07)$ & $33(26.19)$ & \\
\hline$>50$ years & $12(8.22)$ & $14(11.11)$ & \\
\hline \multicolumn{4}{|l|}{ BMI $\left(\mathrm{kg} / \mathrm{m}^{2}\right)$} \\
\hline$<18.5 \mathrm{~kg} / \mathrm{m}^{2}$ & $10(6.85)$ & $5(3.97)$ & \multirow[t]{4}{*}{$0.007^{* *}$} \\
\hline 18.5 to $<24 \mathrm{~kg} / \mathrm{m}^{2}$ & $84(57.53)$ & $50(39.68)$ & \\
\hline 24 to $<27 \mathrm{~kg} / \mathrm{m}^{2}$ & $41(28.08)$ & $53(42.06)$ & \\
\hline$\geq 27 \mathrm{~kg} / \mathrm{m}^{2}$ & $11(7.54)$ & $18(14.29)$ & \\
\hline \multicolumn{4}{|c|}{ White cell in urine, $n(\%)$} \\
\hline No & $135(92.46)$ & $114(90.48)$ & \multirow[t]{2}{*}{0.385} \\
\hline Yes & $11(7.54)$ & $12(9.52)$ & \\
\hline \multicolumn{4}{|l|}{ Sedentary, n (\%) } \\
\hline No & $77(52.74)$ & $54(42.86)$ & \multirow[t]{2}{*}{0.066} \\
\hline Yes & $69(47.26)$ & $72(57.14)$ & \\
\hline \multicolumn{4}{|c|}{ Holding back urine, $n$ (\%) } \\
\hline No & $123(84.25)$ & $88(69.84)$ & \multirow[t]{2}{*}{$0.004^{* *}$} \\
\hline Yes & $23(15.75)$ & $38(30.16)$ & \\
\hline \multicolumn{4}{|c|}{ Anxiety or irritability, n (\%) } \\
\hline No & $88(60.27)$ & $43(34.13)$ & \multirow[t]{2}{*}{$<0.001^{* * *}$} \\
\hline Yes & $58(39.73)$ & $83(65.87)$ & \\
\hline \multicolumn{4}{|l|}{ Sex life, $n(\%)$} \\
\hline No & $17(11.64)$ & $9(7.12)$ & \multirow[t]{2}{*}{0.146} \\
\hline Yes & $129(88.36)$ & $117(92.88)$ & \\
\hline \multicolumn{4}{|l|}{ Contraception, $n$ (\%) } \\
\hline No & $94(64.38)$ & $68(53.97)$ & \multirow[t]{2}{*}{$0.012^{*}$} \\
\hline Yes & $52(35.62)$ & $58(46.03)$ & \\
\hline \multicolumn{4}{|c|}{ Past medical history, $n(\%)$} \\
\hline No & $114(78.08)$ & $90(71.43)$ & \multirow[t]{3}{*}{0.333} \\
\hline Urologic diseases & $28(19.18)$ & $29(23.02)$ & \\
\hline Others & $4(2.74)$ & $7(5.55)$ & \\
\hline \multicolumn{4}{|c|}{ Alcohol consumption, n (\%) } \\
\hline No & $94(64.38)$ & $90(71.43)$ & \multirow[t]{3}{*}{$>0.05$} \\
\hline$\leq 100 \mathrm{~g} / \mathrm{w}$ & $35(23.97)$ & $27(21.43)$ & \\
\hline$>100 \mathrm{~g} / \mathrm{w}$ & $17(11.65)$ & $9(7.14)$ & \\
\hline \multicolumn{4}{|l|}{ Smoking, n (\%) } \\
\hline No & $110(75.34)$ & $8(6.35)$ & \multirow[t]{3}{*}{$<0.001^{* * *}$} \\
\hline$\leq 10$ cigarettes $/ d$ & $26(17.81)$ & $28(22.22)$ & \\
\hline$>10$ cigarettes/d & $10(6.85)$ & $90(71.43)$ & \\
\hline
\end{tabular}

BMI Body Mass Index (obtained as weight divided by height squared)

95\% CI: $1.161-3.014, P=0.029)$ and smoking (OR: 1.453, 95\% CI: $1.313-5.127, P=0.013)$ were the risk factors. The OR, $95 \% \mathrm{CI}$, and $P$-value of each variable were presented in Table 2.
Table 2 Multivariate logistic regression analysis found out the factors related to pain severity prediction

\begin{tabular}{lllc}
\hline Parameters & OR & $\mathbf{9 5 \% ~ C l}$ & P value \\
\hline Age & 2.828 & $1.239-6.648$ & $0.004^{* *}$ \\
Holding back urine & 2.413 & $1.213-4.915$ & $0.005^{* *}$ \\
Anxiety or irritability & 3.511 & $2.034-6.186$ & $<0.001^{* * *}$ \\
Contraception & 2.136 & $1.161-3.014$ & $0.029^{*}$ \\
Smoking & 1.453 & $1.313-5.127$ & $0.013^{*}$ \\
\hline
\end{tabular}

$C l$ confidential interval, $O R$ odd ratio

${ }^{*} P<0.05,{ }^{*} P<0.01$ and ${ }^{* *} P<0.001$

\section{Establishment of the predictive nomogram}

To confirm the relationship between these confirmed risk factors and CP/CPPS, a predicting model of pain severity in patients with CP/CPPS was established. The distributions of variables among CP/CPPS patients between mild pain and moderately to severely pain groups in the training and the validation cohorts were shown in Table 3 . Based on the six variables derived from multivariate logistic regression analysis, we created a nomogram that could be used to predict the pain severity in patients with CP/CPPS. As shown in Fig. 2, the top bar indicated the scale for estimating the risk score of each variable, while the bottom bar corresponds to the pain severity in patients with CP/CPPS.

\section{Apparent performance of the predictive nomogram in the cohort}

To evaluate the calibration and discrimination of the nomogram, the calibration and ROC curves were applied. The calibration curve demonstrated a good agreement in the training cohort (Fig. 3a) and the ROC curve confirmed the predictive value of the nomogram, with the AUC value of 0.781 (Fig. 3b). Meanwhile, the DCA analysis was used to evaluate the clinical utility of this nomogram (Fig. 3c). We then used the validation cohort to verify the calibration, discrimination, and clinical utility of the nomogram. The calibration plot (Fig. 3d), AUC value (Fig. 3e), and DCA analysis (Fig. 3f) derived from the validation cohort showed similar results as the training cohort. These results reflected that the nomogram can precisely and steadily judge pain severity in patients with CP/CPPS.

\section{Discussion}

Prostatitis is a common outpatient disease in urology. Recent research has shown that the prevalence rates of prostatitis in Europe and the USA are 10\% to 14\% [21]. In the USA, this health problem motivates $8 \%$ of urology consultations [1]. Among all types of prostatitis, $\mathrm{CP} / \mathrm{CPPS}$ accounts for most cases. As shown in previous studies, men of all ages and ethnic origins can suffer 
Table 3 Baseline patient and disease characteristics of the training and validation cohorts

\begin{tabular}{|c|c|c|c|c|}
\hline \multirow[t]{2}{*}{ Characteristic } & \multicolumn{2}{|c|}{$\begin{array}{l}\text { Training cohort } \\
(n=192)\end{array}$} & \multicolumn{2}{|c|}{$\begin{array}{l}\text { Validation cohort } \\
(n=80)\end{array}$} \\
\hline & $\begin{array}{l}\text { Mildly pain } \\
(\mathrm{n}=96)\end{array}$ & $\begin{array}{l}\text { Moderately to severely Pain } \\
(n=96)\end{array}$ & $\begin{array}{l}\text { Mildly pain } \\
(n=50)\end{array}$ & $\begin{array}{l}\text { Moderately } \\
\text { to severely } \\
\text { pain } \\
(n=30)\end{array}$ \\
\hline \multicolumn{5}{|l|}{ Age, years } \\
\hline$\leq 30$ years & 37 (38.54) & $31(32.29)$ & $23(46.00)$ & $12(40.00)$ \\
\hline 30 to $\leq 40$ years & $36(37.50)$ & $29(30.21)$ & $16(32.00)$ & $7(23.33)$ \\
\hline 40 to $\leq 50$ years & $17(17.71)$ & $27(28.125)$ & $5(10.00)$ & $6(20.00)$ \\
\hline$>50$ years & $6(6.25)$ & $9(9.375)$ & $6(12.00)$ & $5(16.67)$ \\
\hline \multicolumn{5}{|c|}{ Holding back urine, $n(\%)$} \\
\hline No & $80(83.33)$ & $62(64.58)$ & $43(86.00)$ & $26(86.67)$ \\
\hline Yes & $16(16.67)$ & $34(35.42)$ & $7(14.00)$ & $4(13.33)$ \\
\hline \multicolumn{5}{|c|}{ Anxiety or irritability, n (\%) } \\
\hline No & $57(59.375)$ & $30(31.25)$ & $31(62.00)$ & $13(43.33)$ \\
\hline Yes & $39(40.625)$ & $66(68.75)$ & $19(38.00)$ & $17(56.67)$ \\
\hline \multicolumn{5}{|l|}{ Contraception, $n$ (\%) } \\
\hline No & $62(64.58)$ & $50(52.08)$ & $32(64.00)$ & $13(43.33)$ \\
\hline Yes & $34(35.42)$ & $46(47.92)$ & $18(36.00)$ & $17(56.67)$ \\
\hline \multicolumn{5}{|l|}{ Smoking, $n(\%)$} \\
\hline No & $70(72.92)$ & $6(6.25)$ & $40(80.00)$ & $2(6.67)$ \\
\hline$\leq 10$ cigarettes $/ d$ & $19(19.79)$ & 19 (19.79) & $7(14.00)$ & $9(30.00)$ \\
\hline$>10$ cigarettes/d & $7(7.29)$ & $71(73.96)$ & $3(6.00)$ & $19(63.33)$ \\
\hline
\end{tabular}

$B M I$ Body Mass Index (obtained as weight divided by height squared)

from CP/CPPS, but the morbidity of the disease is more common in men who are younger than 50 years old [1]. Although the clinical presentations are diverse, the main clinical features of prostatitis are pelvic pain and lower urinary tract symptoms [22]. Thus, CP/CPPS is defined as pelvic pain that has presented for at least three months and for which no apparent cause has been found [23].

From recent research, we found that engagement in sedentary work and alcohol consumption had a negative influence while marriage had a positive impact on the prognosis of CP/CPPS [24]. Therefore, the questionnaire we designed included age, BMI, white cells in the urine, NIH-CPSI scores, sedentary, urinary retention, anxiety or irritability, sex life, contraception, past medical history, alcohol consumption, and smoking. Currently, nomograms are prognostic methods that can increase accuracy and make prognoses easier to understand, resulting in better clinical decision making; they are widely used in oncology and medicine [25]. Therefore, in our study, we used multivariate logistic regression analysis to figure out the risk factors for the pain severity in patients with $\mathrm{CP} /$ CPPS and used a nomogram device to predict pain severity in CP/CPPS patients. Through using logistic regression analysis to measure the variables, we found that age, urinary retention, anxiety or irritability, contraception, and smoking were related to the pain severity in patients with CP/CPPS and enrolled those variables in the predictive model. Incorporating these five variables into the nomogram allowed the prediction of pain severity in $\mathrm{CP} / \mathrm{CPPS}$ patients and resulted in the construction of an accurate prediction model of pain severity in CP/CPPS patients. The validation cohort demonstrated good discrimination and calibration power.

For many diseases, age is a potential risk factor. Previous research showed that $\mathrm{CP} / \mathrm{CPPS}$ was more prevalent in older people [26, 27]. Other research showed that younger age had been associated with more CP/ CPPS symptoms [28] and worse QoL [29]. In our study, we found that age is a risk factor for pain severity in $\mathrm{CP} /$ CPPS patients, but the age ranges from 40 to 50 years had a higher risk for pain severity in CP/CPPS patients. In some opinions, sedentary and urinary retention could not cause CP/CPPS, but these variables could intensify pain severity among CP/CPPS due to the distention of the venous plexus of the prostate peripheral zone or chronic congestion of the pelvic cavity when in a sitting position [30]. In our study, we found that urinary retention had a significant correlation with the pain severity in $\mathrm{CP} / \mathrm{CPPS}$ patients. In previous studies, alcohol consumption was related to unchanged or worse symptoms in $\mathrm{CP} /$ 
Points

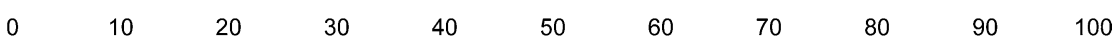

Age

$\overbrace{=<30 y \quad>50 y}^{30-40 y} 40-50 y$

Holding_back_urine

No

Yes

anxiety_or_irritability

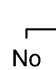

Yes

No

contraception

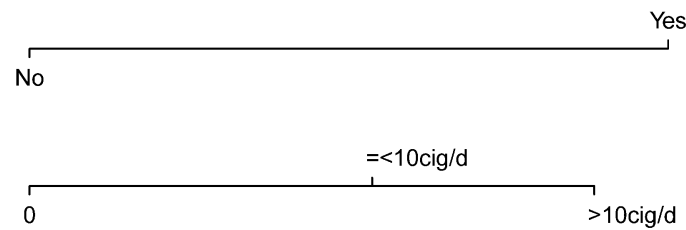

Smoking

Total Points

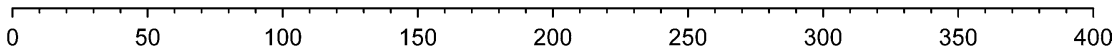

Risk of PIN

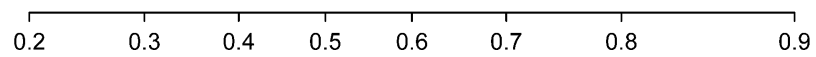

Fig. 2 Novel nomogram of predicting the risk of the severity of pain of CP/CPPS patients. The severity of the pain of CP/CPPS patients nomogram was developed in the cohort, with the use of age, holding back urine, anxiety or irritability, contraception, and smoking

CPPS patients [24]. In our research, through the logistic regression analysis, we found that alcohol consumption was not connected with the pain severity in CP/CPPS patients.

Some researches showed that the frequency of sexual activity, especially the excessive number of sexual intercourse, was related to CP/CPPS [31]. So, we investigate the influence of sexual activity and contraception. In our study, we did not find the relationship between sexual activity with the pain severity in CP/CPPS patients. But we found that contraception was significantly related to the pain severity in CP/CPPS patients. According to previous research, condoms could delay ejaculation resulting in sex lasting longer [32]. In the process of a sexual impulse in humans, the pelvic congestion will regress in about 15-30 min after an orgasm or may last longer without an orgasm [30]. Prolonged sexual activity could increase pelvic congestion. So, one of the possible reasons that condoms could intensify pain severity among $\mathrm{CP} / \mathrm{CPPS}$ may be due to increased pelvic congestion. Smoking tended to enhance pain sensitivity. However, whether smoking affects CP/CPPS is still controversial. In Chen's study, they found that smoking is a harmful factor for CP/CPPS [11], but another study found that smoking resulted in a better symptom relief rate [24]. In our research, we found that smoking is a risk factor for pain severity in CP/CPPS patients.

The correlation between stress and pain severity in CP/CPPS patients has been rarely reported. One study showed that people who are under stress at home or work are 1.5-fold more likely to suffer from CP/CPPS than unstressed people [30]. Recently researches showed that biopsychosocial stress had a significant association with chronic pelvic pain in men [33]. In our study, we found that stress is a risk factor for pain severity in $\mathrm{CP} /$ CPPS patients. However, whether stress causes or results from the pain in CP/CPPS patients was difficult to decide in the present study.

A 2009 revision of the NIH-CPSI called the GU problem index (GUPI) is now the recommended index as it includes questions on pain with bladder filling and bladder emptying [34]. The questions on pain with bladder filling and bladder emptying did not include in the questionnaire we used according to the previous vision of NIH-CPSI. Then, we will add these two questions in our follow-up research. 


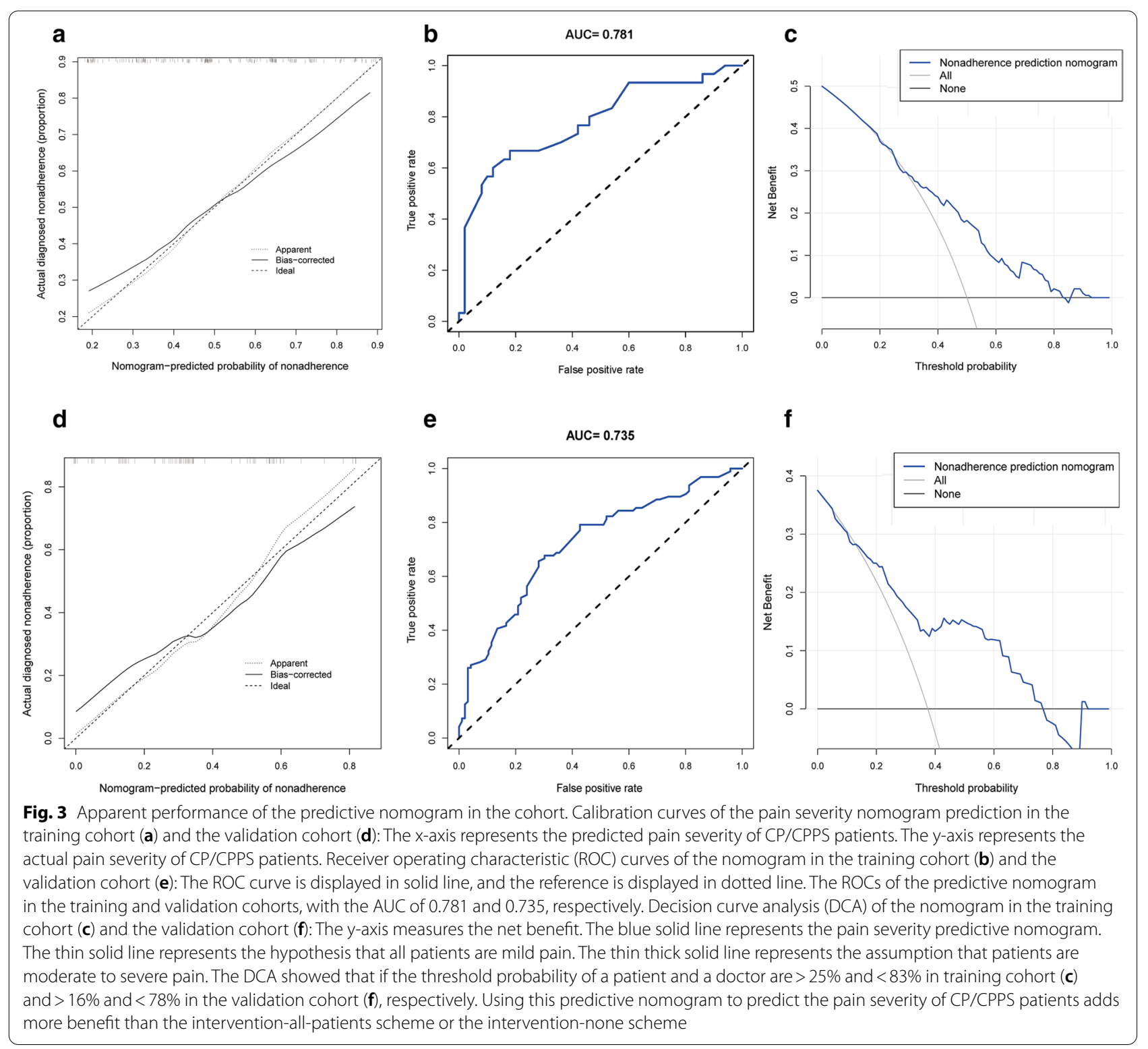

\section{Conclusion}

In summary, age, holding back urine, anxiety or irritability, contraception and smoking were related to the pain severity in patients with CP/CPPS, and the establishment of the nomogram model could accurately assess the pain severity in patients with CP/CPPS to provide novel inspirations for clinicians to design the personalized treatment plan for each CP/CPPS patient who has suffered different encounters.

\section{Supplementary information}

Supplementary information accompanies this paper at https://doi. org/10.1186/s12894-020-00729-9.
Additional file 1: Table S1. Eleven variables were selected for analysis and variables tested.

\section{Abbreviations}

CP/CPPS: Chronic Prostatitis/Chronic Pelvic Pain Syndrome; $\mathrm{NIH}$ : The National Institutes of Health; BPH: Benign prostatic hyperplasia; SAS: Self-Rating Anxiety Scale; Cl: Confidence interval; ROC: Receiver operating characteristic curve; AUC: Area under the curve; DCA: Decision curve analyses; OR: Odds ratio.

\section{Acknowledgments}

Not applicable.

\section{Authors' contributions}

$\mathrm{CL}$ and $\mathrm{MZ}$ designed the research and revised the paper. $\mathrm{HZ}, \mathrm{DN}, \mathrm{HL}, \mathrm{KW}$ collected and summaried the data. MZ, JC, LZ, LL, XZ analysied and interpreted 
the data. JC, MZ drafted the paper. All authors contributed substantial intellectual contributions. All authors read and approved the final manuscript.

\section{Funding}

The National Natural Science Foundation of China 81630019, 81870519 and 81802827. Scientific Research Foundation of the Institute for Translational Medicine of Anhui Province (2017ZHYX02). The Natural Science Foundation of Guangdong Province, China (2017A030313800). Shenzhen Basic Research Project (JCYJ20160429172247015).

\section{Availability of data and materials}

The datasets used and/ or analyzed during the current study available from the corresponding author on reasonable request.

\section{Declarations}

\section{Ethics approval and consent to participate}

Ethical approval was obtained from the Institutional Review Boards of The First Affiliated Hospital of Anhui Medical University. Written informed consent was obtained from all participants.

\section{Consent for publication}

Not applicable.

\section{Competing interests}

All the authors state they have no conflicts of interest.

\section{Author details}

1 Department of Urology, The First Affiliated Hospital of Anhui Medical University, Hefei, People's Republic of China. ${ }^{2}$ The Institute of Urology, Anhui Medical University, Hefei, People's Republic of China. ${ }^{3}$ The Second Clinical College of Anhui Medical University, Hefei, Anhui, People's Republic of China. ${ }^{4}$ Anhui Province Key Laboratory of Genitourinary Diseases, Anhui Medical University, Hefei, People's Republic of China. ${ }^{5}$ Department of Urology, b Reproductive Medicine Center, Xiangya Hospital, Central South University, Changsha, People's Republic of China. ${ }^{6}$ Institute of Urology of Shenzhen University, The Third Affiliated Hospital of Shenzhen University, Shenzhen Luohu Hospital Group, Shenzhen, People's Republic of China.

Received: 5 May 2020 Accepted: 24 September 2020 Published online: 07 October 2020

\section{References}

1. Collins MM, Stafford RS, O'Leary MP, Barry MJ. How common is prostatitis? A national survey of physician visits. J Urol. 1998;159(4):1224-8.

2. Schwartz ES, Xie A, La JH, Gebhart GF. Nociceptive and inflammatory mediator upregulation in a mouse model of chronic prostatitis. Pain. 2015;156(8):1537-44. https://doi.org/10.1097/j.pain.0000000000000201.

3. Rees J, Abrahams M, Doble A, Cooper A, Prostatitis Expert Reference Group (PERG). Diagnosis and treatment of chronic bacterial prostatitis and chronic prostatitis/chronic pelvic pain syndrome: a consensus quideline. BJU Int. 2015;116(4):509-25. https://doi.org/10.1111/bju.13101.

4. Liang CZ, Li HJ, Wang ZP, et al. The prevalence of prostatitis-like symptoms in China. J Urol. 2009;182(2):558-63. https://doi.org/10.1016/j. juro.2009.04.011.

5. Krieger JN, Nyberg L Jr, Nickel JC. NIH consensus definition and classification of prostatitis. JAMA. 1999;282(3):236-7. https://doi.org/10.1001/ jama.282.3.236.

6. Murphy SF, Schaeffer AJ, Thumbikat P. Immune mediators of chronic pelvic pain syndrome. Nat Rev Urol. 2014;11(5):259-69. https://doi. org/10.1038/nrurol.2014.63.

7. Magistro G, Wagenlehner FME, Grabe M, Weidner W, Stief CG, Nickel JC. Contemporary management of chronic prostatitis/chronic pelvic pain syndrome. Eur Urol. 2016;69(2):286-97. https://doi.org/10.1016/j.eurur 0.2015 .08 .061

8. Magri V, Wagenlehner FM, Marras E, et al. Influence of infection on the distribution patterns of $\mathrm{NIH}$-Chronic Prostatitis Symptom Index scores in patients with chronic prostatitis/chronic pelvic pain syndrome (CP/CPPS) Exp Ther Med. 2013;6(2):503-8. https://doi.org/10.3892/etm.2013.1174.

9. Tadros NN, Shah AB, Shoskes DA. Utility of trigger point injection as an adjunct to physical therapy in men with chronic prostatitis/chronic pelvic pain syndrome. Transl Androl Urol. 2017;6(3):534-7. https://doi. org/10.21037/tau.2017.05.36.

10. Wagenlehner FM, van Till JW, Magri V, et al. National Institutes of Health Chronic Prostatitis Symptom Index (NIH-CPSI) symptom evaluation in multinational cohorts of patients with chronic prostatitis/chronic pelvic pain syndrome. Eur Urol. 2013;63(5):953-9. https://doi.org/10.1016/j.eurur 0.2012 .10 .042

11. Chen X, Hu C, Peng Y, et al. Association of diet and lifestyle with chronic prostatitis/chronic pelvic pain syndrome and pain severity: a case-control study. Prostate Cancer Prostatic Dis. 2016;19(1):92-9. https://doi. org/10.1038/pcan.2015.57.

12. Zhang R, Sutcliffe $S$, Giovannucci $E$, et al. Lifestyle and risk of chronic prostatitis/chronic pelvic pain syndrome in a cohort of United States male health professionals. J Urol. 2015;194(5):1295-300. https://doi. org/10.1016/j.juro.2015.05.100.

13. Magistro G, Wagenlehner FME, Grabe M, et al. Contemporary management of chronic prostatitis/chronic pelvic pain syndrome. Eur Urol. 2016;69(2):286-97. https://doi.org/10.1016/j.eururo.2015.08.061.

14. Lee $\mathrm{SH}$, Lee BC. Electroacupuncture relieves pain in men with chronic prostatitis/chronic pelvic pain syndrome: three-arm randomized trial. Urology. 2009;73(5):1036-41. https://doi.org/10.1016/j.urolo gy.2008.10.047.

15. Litwin MS, McNaughton-Collins M, Fowler FJ Jr, et al. The National Institutes of Health chronic prostatitis symptom index: development and validation of a new outcome measure. Chronic Prostatitis Collaborative Research Network. J Urol. 1999;162(2):369-75. https://doi.org/10.1016/ s0022-5347(05)68562-x.

16. Barry MJ, Simmons LH. Prevention of prostate cancer morbidity and mortality: primary prevention and early detection. Med Clin North Am. 2017;101(4):787-806. https://doi.org/10.1016/j.mcna.2017.03.009.

17. Manuel RG, Zelber SS, Trenell M. Treatment of NAFLD with diet, physical activity and exercise. J Hepatol. 2017;67(4):829-46. https://doi. org/10.1016/j.jhep.2017.05.016.

18. Anwar T, Cooper CS, Lockwood G, Storm DW, et al. Assessment and validation of a screening questionnaire for the diagnosis of pediatric bladder and bowel dysfunction. J Pediatr Urol. 2019;15(5):528.e1-.e8. https://doi. org/10.1016/j.jpurol.2019.07.016.

19. Dunstan DA, Scott N, Todd AK. Screening for anxiety and depression: reassessing the utility of the Zung scales. BMC Psychiatry. 2017;17(1):329. https://doi.org/10.1186/s12888-017-1489-6.

20. Nelson PR, Chen P, Battista DR, et al. Randomized trial to compare smoking cessation rates of snus, with and without smokeless tobacco health-related information, and a nicotine lozenge. Nicotine Tob Res. 2019;21(1):88-94. https://doi.org/10.1093/ntr/nty011.

21. Bajpayee P, Kumar K, Sharma S, et al. Prostatitis: prevalence, health impact and quality improvement strategies. Acta Pol Pharm. 2012;69(4):571-9.

22. Nickel JC, Nyberg LM, Hennenfent M. Research guidelines for chronic prostatitis: consensus report from the first National Institutes of Health International Prostatitis Collaborative Network. Urology. 1999;54(2):22933. https://doi.org/10.1016/s0090-4295(99)00205-8.

23. Nickel JC, Alexander R, Anderson R, et al. Prostatitis unplugged? Prostatic massage revisited. Tech Urol. 1999;5(1):1-7.

24. Zhang J, Zhang X, Cai Z, Li N, Li H. The lifetime risk and prognosis of chronic prostatitis/chronic pelvic pain syndrome in the middle-aged Chinese males. Am J Mens Health. 2019;13(4):1557988319865380. https ://doi.org/10.1177/1557988319865380.

25. Wei L, Champman S, Li X, et al. Beliefs about medicines and non-adherence in patients with stroke, diabetes mellitus and rheumatoid arthritis: a cross-sectional study in China. BMJ Open. 2017;7(10):e017293. https://doi. org/10.1136/bmjopen-2017-017293.

26. Cheah PY, Liong ML, Yuen KH, et al. Chronic prostatitis: symptom survey with follow-up clinical evaluation. Urology. 2003;61(1):60-4. https://doi. org/10.1016/s0090-4295(02)02081-2.

27. Wang $Y, H e L$, Zhou Z, et al. The association between metabolic syndrome and the National Institutes of Health Chronic Prostatitis Symptom Index: results from 1673 men in China. Urology. 2013;82(5):1103-7. https://doi. org/10.1016/j.urology.2013.06.007. 
28. Schaeffer AJ, Landis JR, Knauss JS, et al. Demographic and clinical characteristics of men with chronic prostatitis: the national institutes of health chronic prostatitis cohort study. J Urol. 2002;168(2):593-8.

29. McNaughton Collins M, Pontari MA, O'Leary MP, et al. Quality of life is impaired in men with chronic prostatitis: the Chronic Prostatitis Collaborative Research Network. J Gen Intern Med. 2001;16(10):656-62. https:// doi.org/10.1111/j.1525-1497.2001.01223.x.

30. Pavone C, Caldarera E, Liberti P, et al. Correlation between chronic prostatitis syndrome and pelvic venous disease: a survey of 2,554 urologic outpatients. Eur Urol. 2000;37(4):400-3. https://doi.org/10.1159/00002 0185.

31. Gallo L. Effectiveness of diet, sexual habits and lifestyle modifications on treatment of chronic pelvic pain syndrome. Prostate Cancer Prostatic Dis. 2014;17(3):238-45. https://doi.org/10.1038/pcan.2014.18.

32. Randolph ME, Pinkerton SD, Bogart LM, Cecil H, Abramson PR. Sexual pleasure and condom use. Arch Sex Behav. 2007;36(6):844-8. https://doi. org/10.1007/s10508-007-9213-0.
33. Anderson RU, Orenberg EK, Morey A, Chavez N, Chan CA. Stress induced hypothalamus-pituitary-adrenal axis responses and disturbances in psychological profiles in men with chronic prostatitis/chronic pelvic pain syndrome. J Urol. 2009;182(5):2319-24. https://doi.org/10.1016/j. juro.2009.07.042.

34. Clemens JQ, Calhoun EA, Litwin MS, et al. Validation of a modified National Institutes of Health chronic prostatitis symptom index to assess genitourinary pain in both men and women. Urology. 2009;74(5):983987.e9873. https://doi.org/10.1016/j.urology.2009.06.078.

\section{Publisher's Note}

Springer Nature remains neutral with regard to jurisdictional claims in published maps and institutional affiliations.
Ready to submit your research? Choose BMC and benefit from:

- fast, convenient online submission

- thorough peer review by experienced researchers in your field

- rapid publication on acceptance

- support for research data, including large and complex data types

- gold Open Access which fosters wider collaboration and increased citations

- maximum visibility for your research: over $100 \mathrm{M}$ website views per year

At BMC, research is always in progress.

Learn more biomedcentral.com/submissions 